\title{
2744. Ultimate shear performance and friction sliding response of laminated elastomeric bridge bearings
}

\author{
Yue $\mathbf{L i}^{1}$, Qian $\mathbf{L i}^{2}$, Qiqi $\mathbf{W u}^{3}$ \\ ${ }^{1,3}$ School of Civil Engineering, North China University of Technology, Beijing, China \\ ${ }^{2}$ Research Institute of Highway of Ministry of Communications, Beijing, China \\ ${ }^{2}$ Corresponding author \\ E-mail: 17iyue_26@163.com,27ian.li@rioh.cn, ${ }^{3}$ vicki577@hotmail.com \\ Received 9 March 2017; received in revised form 31 July 2017; accepted 14 September 2017 \\ DOI https://doi.org/10.21595/jve.2017.18321
}

Check for updates

\begin{abstract}
In major earthquakes, friction sliding of common laminated elastomeric bearings limits the force transmitted from the superstructure to the substructure. Experiments were carried out to investigate the ultimate shear performance and the friction sliding response of laminated elastomeric bridge bearings. First, the hysteresis curve of the common laminated elastomeric bearings present narrow ribbon which meant the energy dissipation capacity induced by the shear deformation was weak. The ultimate shear deformation of the bearings could reach $300 \%$ to $400 \%$ of the elastomeric thickness. The damage of bearings was mainly focused on the rubber layer fracture. Second, the energy dissipation capacity of elastomeric bearings induced by the friction sliding was larger than the shear deformation, and was similar with the lead rubber bearing. Since the total displacement include both elastomer shear deformation and sliding components, the dissipated energy continuously increased with the increasing of the sliding distance. When the tests finished, the bearings were basic intact, only the rubber surface was worn down. Last, the bilinear elastic-plastic model is proposed to take as the theoretical model of the elastomeric bearing with friction sliding for the research and design of bridge in earthquake.
\end{abstract}

Keywords: laminated elastomeric bearings, shear performance, friction sliding response, experiment.

\section{Introduction}

In recent earthquakes in China, the damage of middle and small span girder bridges are mainly consisted of girders falling, bearings sliding, collision of the adjacent girders in the expansion joint, and restrainer or abutment damage. Meanwhile, pier damage was uncommon [1]. The reason is that laminated elastomeric bearings are widely used in girder bridges in China. The bearings are installed directly on the top of the pier without effective connection between the piers and girders. In major earthquakes, the relative friction sliding between the bearing and the contact surface of the pier reduces the horizontal seismic load transmitted to the substructure, which plays a role in seismic isolation [1]. This is different from the assumption in the bridge seismic design, which requires a load transmission path without interruption. The bearings do not displace or become damaged, and the seismic energy is dissipated in the plastic hinge at the bottom of piers [2].

As an important component connected the upper and superstructure in bridges, the bearing damage has a large influence on the seismic performance of bridges during an earthquake [3]. Iemura et al. [4] studied the effect of steel bearing damage on the seismic damage model of bridges and found that during an earthquake, the mechanical property of the damaged sliding steel bearing is similar to the fixed bearing, which resulted an excessive seismic force being transferred to the bottom of the piers. Y. Kajita et al. [5] discussed the seismic response of elevated continuous girder bridges with damaged bearings. M. Okazaki et al. [6] proposed that there were two types of bearing damage models, the first model supposed a fixed connection between the upper and superstructure after the bearing was damaged, and the second supposed that the upper and the superstructure were completely separated after the bearing was damaged. S. Kim et al. [7] proposed a damage model of bearings based on the change of the friction coefficient and discussed the failure state of movable bearings in an earthquake. 
However, research on the ultimate failure state and the energy dissipation due to friction sliding is insufficient. Stanton and Roeder [8] suggested that the maximum shear deformation of elastomeric bearings was $75 \%$ in normal design conditions. Schrage [9] studied the sliding property of the elastomeric bearing on the concrete surface. Mori [10] found that the ultimate shear deformation of the elastomeric bearing without being fixed to the two sides could reach $150-225 \%$. Filipov [11] discussed the effect of the bearing sliding friction on the seismic performance of bridges. Based on the principle of quasi isolation, J. S. Steelman et al. [12, 13] proposed the sliding friction mechanical model of elastomeric bearings during an earthquake and analyzed the effect of the bearing sliding on the seismic performance of bridges. Buckle et al. [14] studied the stability of elastomeric bearings under high shear deformation and analyzed the effect of shear deformation on the vertical critical bearing capacity of the bearing. Li Jianzhong et al. $[15,16]$ proposed the effective control method of the bridge superstructure displacement and discussed the seismic factors affecting the sliding of the elastomeric bearing. Wang Dongsheng et al. $[17,18]$ analyzed the effect of the bearing frictional sliding on the seismic response of simple supported girder bridges. Xie Xu et al. [19] studied the effect of bearing failure on the seismic response of the restrainer in bridges. Wang Junjie et al. [20] proposed the restoring mechanism model considering the failure process of bearings and analyzed the effect of the bearing damage on the seismic response of continuous girder bridges.

To fully ascertain the ultimate shear failure state and friction sliding performance of laminated elastomeric bearings, low-frequency cyclic loading tests were conducted. At the same time, the results were compared with a LRB.

\section{Experiment overview}

The experimental apparatus was specifically designed to realistically reflect field conditions for the full-scale bridge bearing test specimens (as shown in Fig. 1). Vertical loading was imposed on a bearing using a $4000 \mathrm{kN}$ capacity actuator. The use of actuator allowed the vertical load to be maintained at a specified target of simulated gravity load regardless of the lateral displacement of the bearing. Steel pad was used to simulate bridge substructures which was secured to the strong floor.

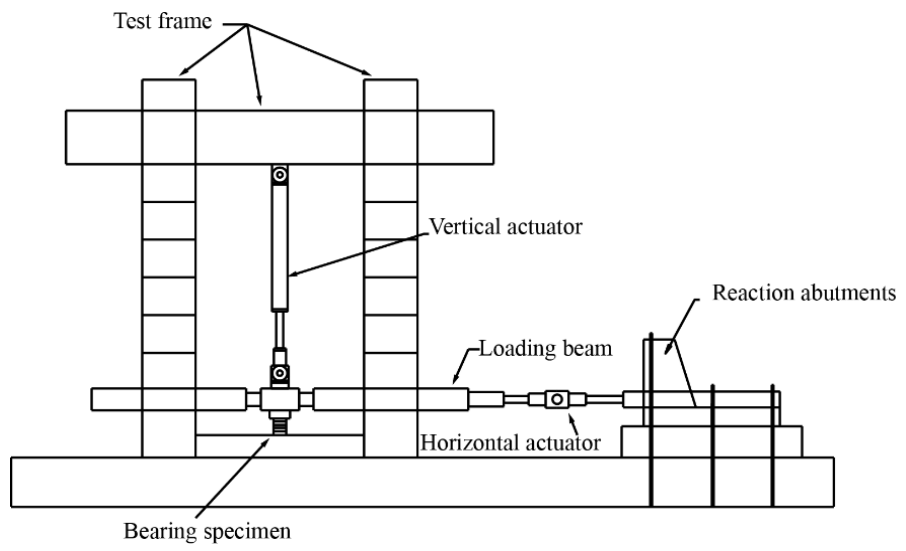

Fig. 1. Testing setup elevation

Referring to the Series of elastomeric pad bearings for highway bridges in China [22], a series of laminated elastomeric bearing specimens were fabricated with the parameters listed in Table 1. In the ultimate shear failure test, the two sides of the bearings were connected with the loading device. In the friction sliding test, the bearings were positively connected at their top surface with the loading device but not anchored at their base against horizontal motion at the elastomer-to-substructure interface. Their bases were permitted to slide on the steel pad. The LRB 
was circular with a diameter of $600 \mathrm{~mm}$. The height of the LRB was $130 \mathrm{~mm}$ totally in which the thickness of the elastomeric layers is $60 \mathrm{~mm}$. There were 4 lead cores with a diameter of $77 \mathrm{~mm}$ in the LRB. Two connecting plates were placed on the top and bottom of the bearing. The specimen of LRB is showed in Fig. 3.

Table 1. Scheme of the bearing test

\begin{tabular}{|c|c|c|c|c|c|}
\hline Type of tests & \multicolumn{3}{|c|}{ Bearing models } & $\begin{array}{c}\text { Total thickness of } \\
\text { elastomeric laver }(\mathrm{mm})\end{array}$ & $\begin{array}{c}\text { Vertical } \\
\text { load (MPa) }\end{array}$ \\
\hline \multirow{3}{*}{$\begin{array}{l}\text { Ultimate shear } \\
\text { failure test }\end{array}$} & S-1 & \multirow{3}{*}{$\begin{array}{l}\text { Laminated } \\
\text { elastomeric } \\
\text { bearings }\end{array}$} & GYZ400×80 & 48 & 4 \\
\hline & S-2 & & GYZ 400×107 & 60 & 6 \\
\hline & S-3 & & GYZ 400×107 & 60 & 8 \\
\hline \multirow{5}{*}{$\begin{array}{l}\text { Frictional sliding } \\
\text { test }\end{array}$} & M-1 & \multirow{5}{*}{$\begin{array}{l}\text { Laminated } \\
\text { elastomeric } \\
\text { bearings }\end{array}$} & GJZ500×550×78 & 48 & 4 \\
\hline & M-2 & & GJZ500×550×78 & 48 & 6 \\
\hline & M-3 & & GJZ500×550×78 & 48 & 8 \\
\hline & M-4 & & GJZ500×550×78 & 48 & 10 \\
\hline & M-5 & & GJZ500×550×87 & 60 & 4 \\
\hline $\begin{array}{l}\text { Low-frequency } \\
\text { cyclic loading test }\end{array}$ & Q-1 & $\begin{array}{c}\text { Lead Rubber } \\
\text { Bearing }\end{array}$ & Y4Q600×130G1.0 & 60 & 6 \\
\hline
\end{tabular}

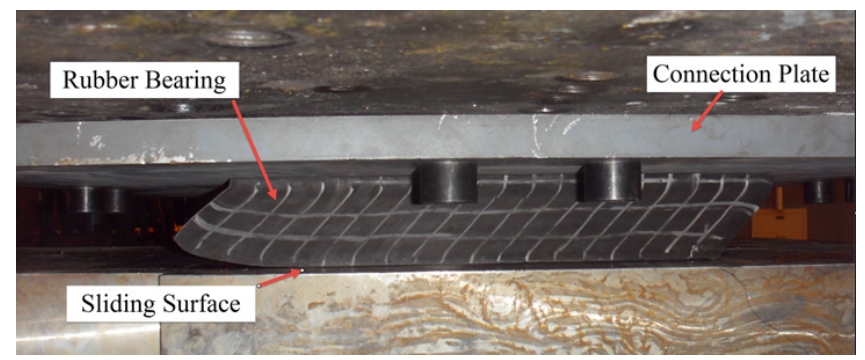

Fig. 2. Specimen in the friction sliding test

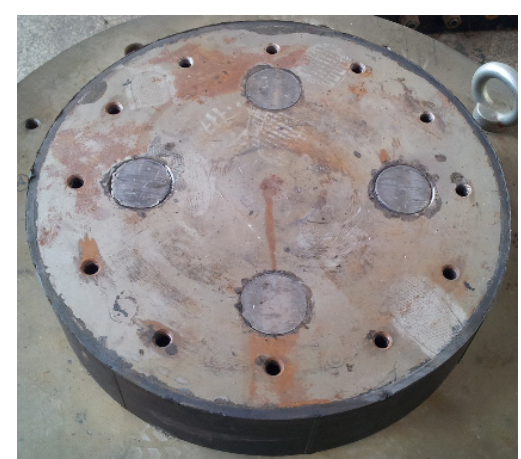

Fig. 3. Lead rubber bearing in the test

In the tests, vertical loading was controlled by the force, which applied a certain pressure load on the bearings. In the horizontal direction, the loading was controlled by the displacement. Under the low-frequency cyclic load, the shear deformation amplitude $(E)$ that the ratio of the loading displacement and the elastomeric layer thickness of the bearings reached $50 \%, 100 \%, 150 \%$, $200 \%, 250 \%$, and $300 \%$.

\section{Experimental phenomena}

\subsection{Ultimate shear failure test of elastomeric bearings}

During the test, with the increasing of shear deformation, the bearing was gradually damaged, 
and the damage phenomenon of the elastomeric bearings is similar. Taking the S-3 as an example, when $E=200 \%$, local failure was detected on the bearings, such as the protective rubber layer separated from the bearing body and expanded outward (as shown in Fig. 4). When $E=300 \%$, internal failure occurred, and fracture noise of the elastomeric layer appeared during the test. When $E$ increased beyond $350 \%$ (as shown in Fig. 5), the elastomeric layer was completely broken at different components, and the shear stiffness of the bearing was lost.

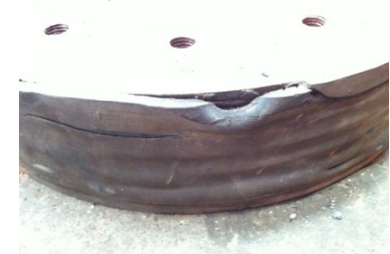

a) Protective rubber layer separated from the body

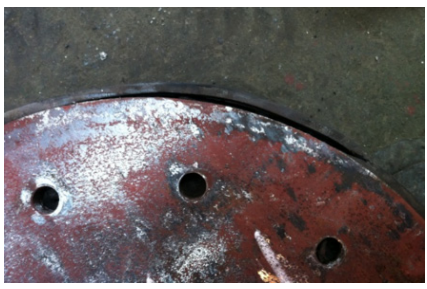

b) Protective rubber layer striped

Fig. 4. Partial failure of the bearing when $E=200 \%$

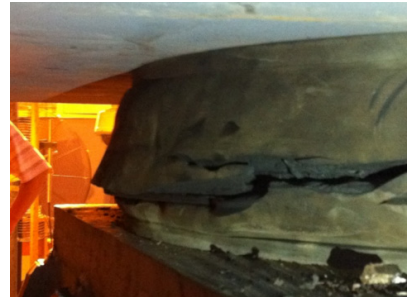

a) Rubber bearing layer ruptured (S-3)

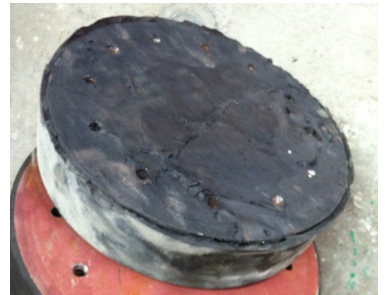

b) Rupture surface of shear failure (S-3)

Fig. 5. Shear failure of the bearings after $E \geq 350 \%$

Under the low-frequency cyclic loading, the hysteresis curve of the laminated elastomeric bearings is shown in Fig. 6. Due to the residual deformation of the bearings, the hysteresis curve presents a narrow zonal shape which means only a small amount of energy dissipated. When $E$ remains less than $200 \%$, the bearings are still in the elastic deformation stage. After $E$ surpasses $300 \%$, the shear stiffness of the bearings will be degenerated, and the hysteresis curve will present a "Z" shape. Simultaneously, the energy dissipation in single cycle gradually increases.

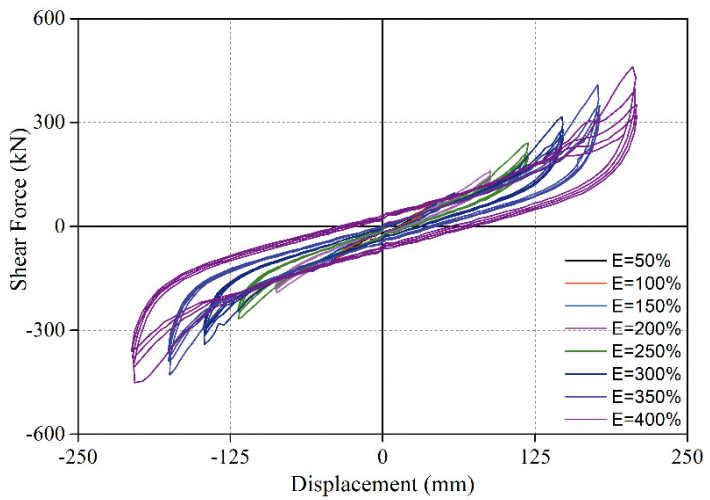

Fig. 6. Hysteresis curve of the laminated elastomeric bearing (S-3)

\subsection{Friction sliding test of the elastomeric bearings}

In the friction sliding tests, the damage phenomenon of the elastomeric bearings is similar each other. Taking the M-2 as an example, the typical displacement process during the test is shown in 
Fig. 7. When $E<100 \%$, accompanying small friction sliding, the elastic shear deformation mainly occurred in the bearing (as shown in Fig. 7(a)). The hysteresis curve presents a linear narrow shape (as shown in Fig. 8). With the increasing of the displacement, the bearing experienced a longer friction sliding distance. Warpage deformation occurred at the corner of the bearings (as shown in Fig. 7(b)). The hysteresis curve presented bilinear distributions and was no longer linear. When $E$ reached $200 \%$, the warpage deformation at the corner of the bearing further increased (as shown in Fig. 7(c)). At the same time, the maximum displacement reached $55 \mathrm{~mm}$, and the maximum shear deformation reached $65 \mathrm{~mm}$ (as shown in Fig. 9). Thereafter, the maximum shear deformation of the bearing remained constant, while the sliding distance of the bearing increased. After the test finished, despite the bottom elastomeric layer being stripped off, the bearing returned to the original status and remained roughly intact without shear failure of the elastomeric layers.

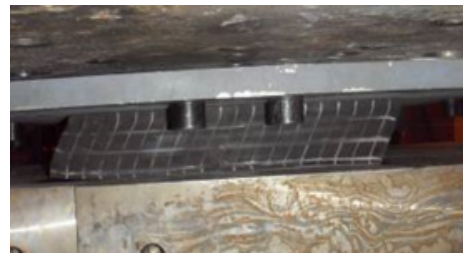

a) $E=50 \%$

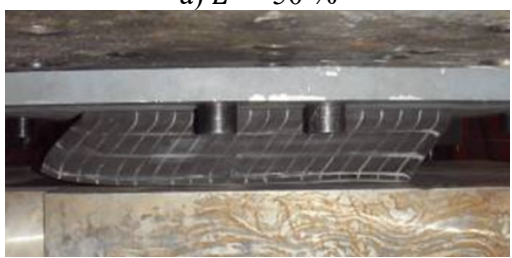

c) $E=200 \%$

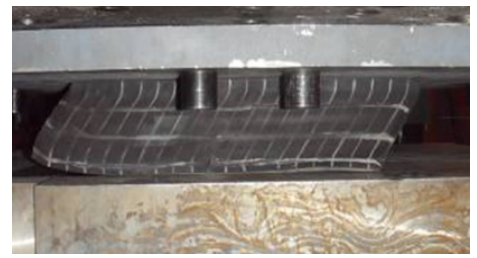

b) $E=100 \%$

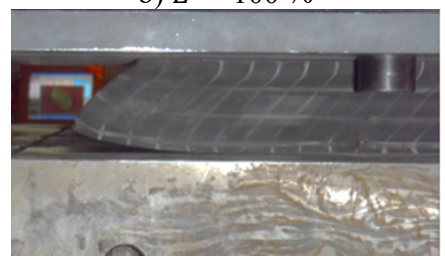

d) $E=300 \%$

Fig. 7. Friction sliding phenomenon (M-2)

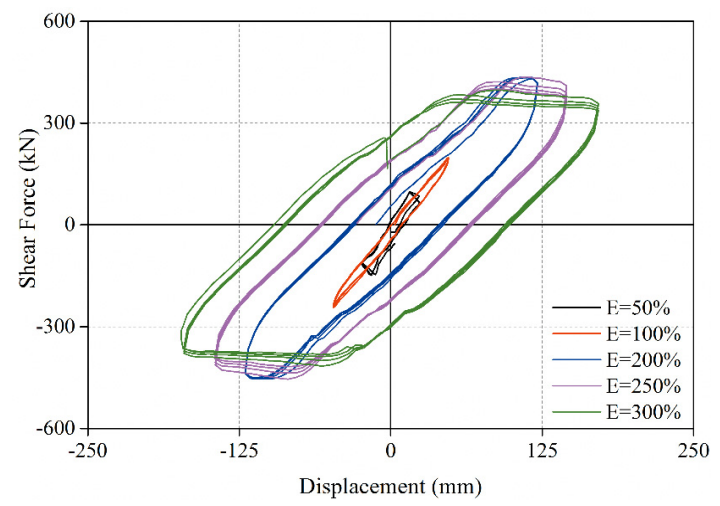

Fig. 8. Hysteresis curve of the bearing sliding friction (M-2)

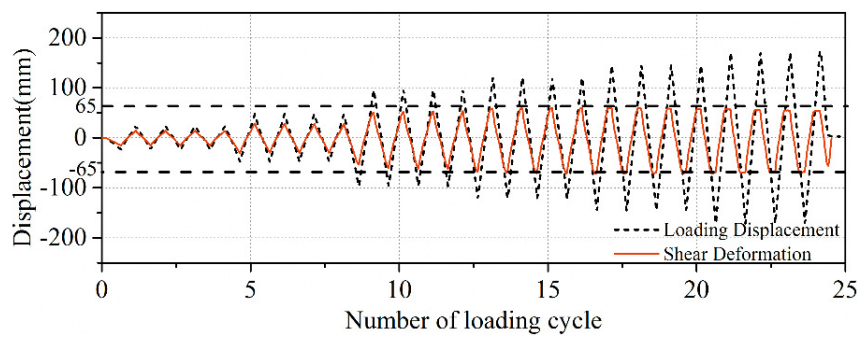

Fig. 9. History curve of the friction sliding displacement 


\subsection{Cyclic load test of the lead rubber bearings}

The energy dissipation of the lead rubber bearing is mainly fulfilled by the lead core deformation. Under a horizontal cyclic load, the stiffness after yielding of the bearing is slightly decreased, and the energy dissipation is increased with the shear deformation. During the test, the energy dissipation capacity of the lead rubber bearing presents good stability. No abnormal appearance was observed, and the hysteresis curve was always fuller (as shown in Fig. 10). After the test, the bearing was essentially restored to its original condition.

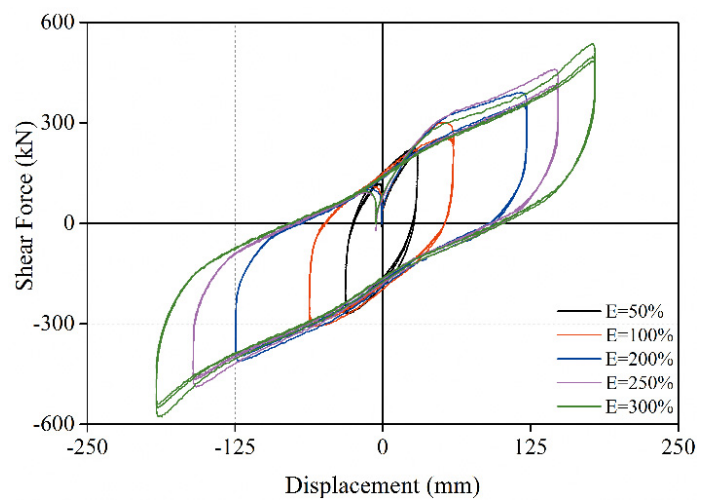

Fig. 10. Hysteresis curve of LRB

\section{Experiment results analysis}

\subsection{Energy dissipation capacity of the bearings}

Under cyclic load, the area surrounded by the hysteresis curve represents the energy dissipation capacity of the bearing. During the ultimate shear failure test of the elastomeric bearings and the cyclic loading test of the lead rubber bearing, the energy dissipation only depends on the shear deformation of the bearing. However, during the friction sliding test, the energy dissipation not only relies on the shearing deformation but also the friction sliding. Due to the mechanism different, it is necessary to compare and analyze the three types of energy dissipation forms. S-3, M-5 and Q-1 represent the three target specimens with identical thicknesses of elastomeric layers. Their energy dissipation capacity was analyzed (as shown in Fig. 11).

In Fig. 11, it can be observed that the hysteresis curve of S-3 always presents a narrow strip shape in every stage, and the energy dissipation capacity was poorer than M-5 and Q-1. While the LRB(Q-1) specimen dissipated energy at the beginning, shear deformation occurred, and the hysteresis curve presents a full spindle shape.

From the relationship curve between the energy dissipation and the shear deformation, it can be found that before $E<200 \%$, both in the ultimate shear failure test and in the friction sliding test, the energy dissipation capacity of the bearings is always less than the lead rubber bearing (as shown in Fig. 12). The reason is mainly that the lead core in the lead rubber bearing began to dissipate energy with little deformation, while the elastomeric bearing was still in its elastic deformation state. The residual deformation and sliding displacement was low, which lead to the poor energy dissipation. When $E$ reached $200 \%$, with the increasing of sliding displacement, the dissipated energy due to friction gradually increased. The hysteresis curve transformed from a narrow band to a full spindle shape. After $E>200 \%$, the dissipated energy of the elastomeric bearing by friction was larger than the lead rubber bearing. Compared to the results of M-5 and Q-1, when $E$ was equal to $50 \%$ and $100 \%$, respectively, the dissipated energy of M-5 was $14 \%$ and $30 \%$ of Q-1 in a single cycle. When E increased to $250 \%$ and $300 \%$, respectively, the dissipated energy of M-5 was $109 \%$ and $126 \%$ of Q-1 in a single cycle. 
It can be found that only the sliding friction made the elastomeric bearing dissipate more energy. With the increasing of sliding displacement, the more energy dissipated, the closer the elastomeric bearing could reach to the energy dissipation capacity of the LRB. The energy dissipation capacity of the LRB increased with the shear deformation and presented an approximately positive proportion.

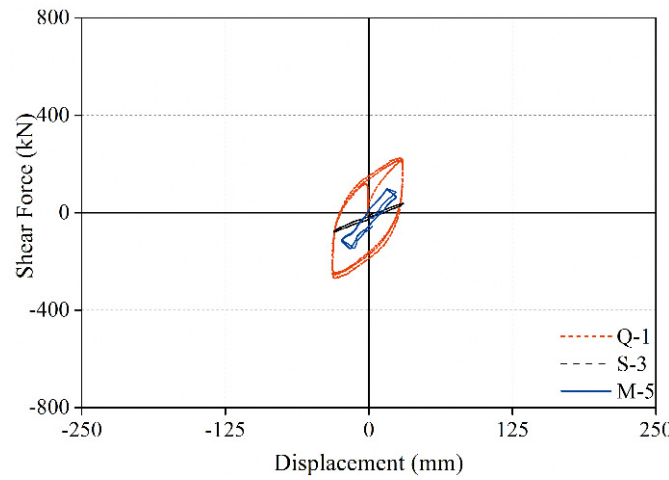

a) $E=50 \%$

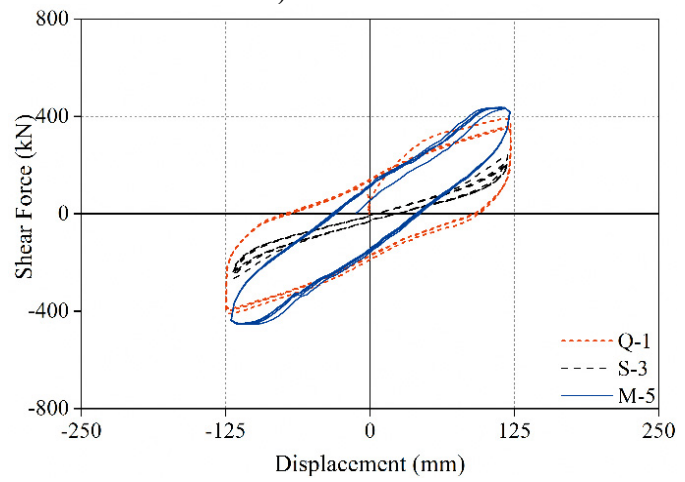

c) $E=200 \%$

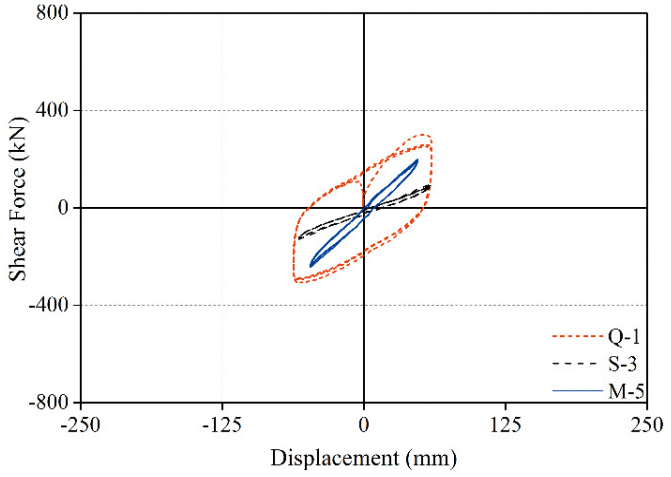

b) $E=100 \%$

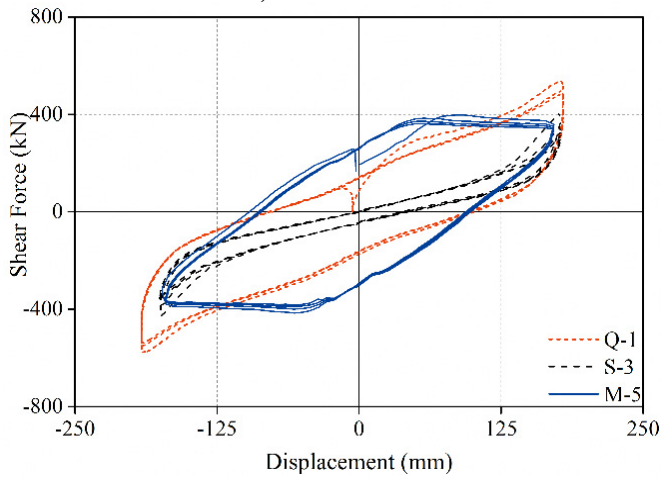

d) $E=300 \%$

Fig. 11. The hysteresis curve of the bearings in different stages

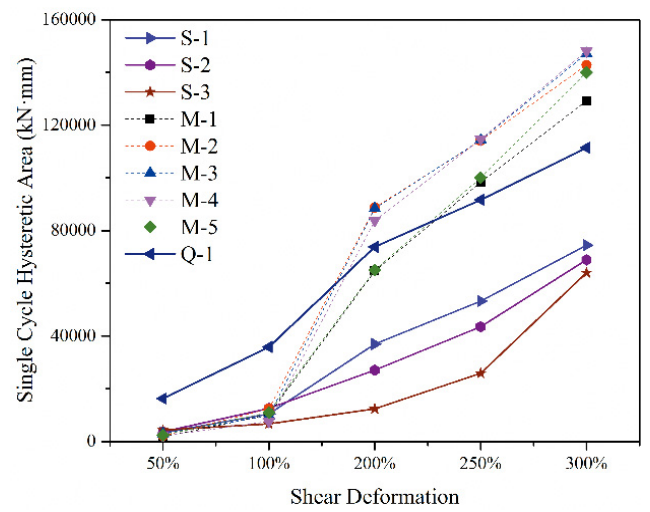

Fig. 12. Shear deformation and energy dissipation curve

\subsection{Analysis of the friction sliding test}

To clarify the effect of the friction sliding on the energy dissipation capacity of the bearings, the results of the four bearings (M-1-M-4) with identical elastomeric layer thicknesses were 
analyzed.

\subsubsection{Shear deformation of the bearings}

The shear deformation of the bearings is separated the sliding displacement from the total loading displacement. Fig. 13 illustrates the shear deformation of the bearings in the test. It can be observed that the shear deformation increased with the vertical load increased (as shown in Fig. 14). When the vertical loads were $4 \mathrm{MPa}, 6 \mathrm{MPa}, 8 \mathrm{MPa}$, and $10 \mathrm{MPa}$, the average maximum shear deformation values due to the bearing sliding were $32 \mathrm{~mm}, 35 \mathrm{~mm}, 44$ $\mathrm{mm}$, and $53 \mathrm{~mm}$, respectively, which are $67 \%, 73 \%, 92 \%$, and $110 \%$ of the total elastomeric thickness, respectively.

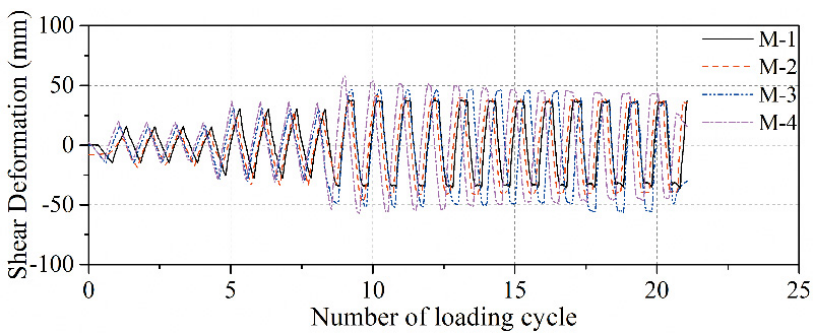

Fig. 13. History curve of the shear deformation in the test

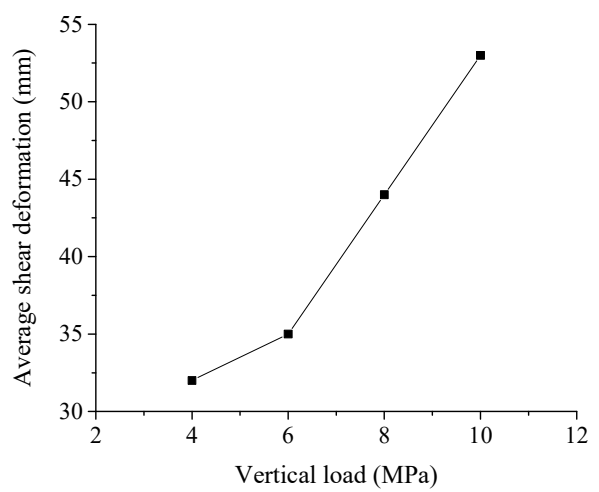

Fig. 14. Effect of vertical load on shear deformation

\subsubsection{Equivalent stiffness}

Under vertical loads, the equivalent stiffness values are similar to each other. The variation trend of the equivalent stiffness degradation curve of the elastomeric bearing is similar and presents a nearly linear shape (as shown in Fig. 15). The equivalent stiffness decreases with the increasing of the shear deformation.

\subsubsection{Friction force and friction coefficient}

The variation of the friction force under different vertical loads is represented by the load-displacement curve of a single monotonic loading process. With an increase in the vertical load, the friction force increased (as shown in Fig. 16). The bearing stiffness shows an obvious hardening effect. The friction coefficient is inversely proportional to the vertical load. When $P=4 \mathrm{MPa}$, the friction coefficient $\mu=0.30-0.40$; when $P=6 \mathrm{MPa}, \mu=0.20-0.30$; when $P=8 \mathrm{MPa}, \mu=0.15-0.25$ (as shown in Fig. 17). 


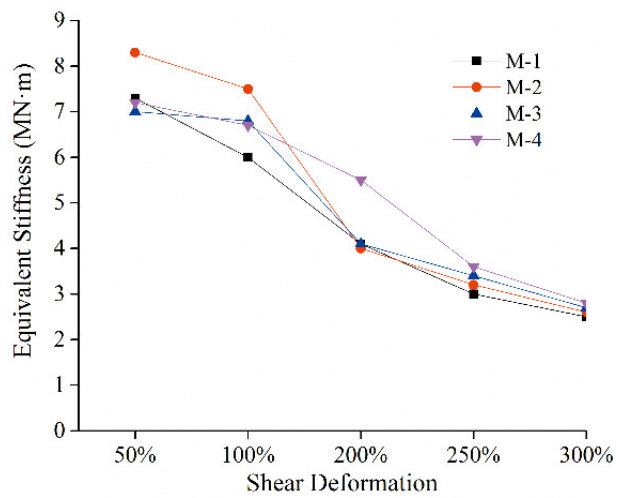

Fig. 15. Equivalent stiffness of the bearings under vertical load

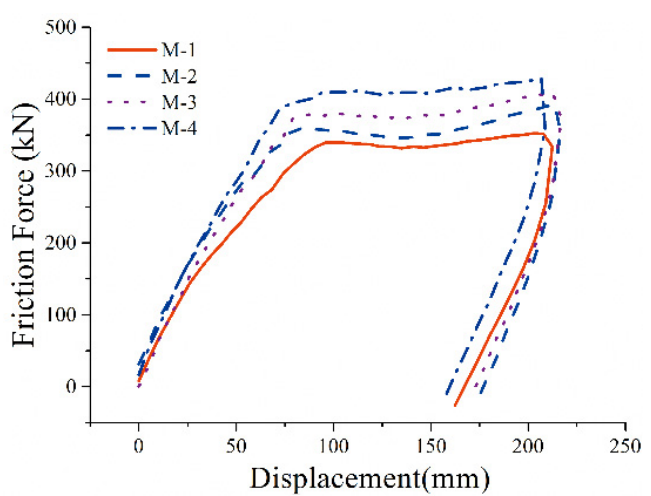

Fig. 16. Relationship of friction force and displacement

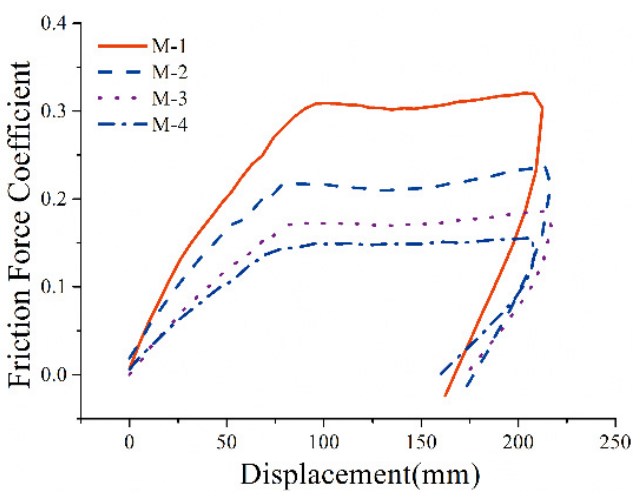

Fig. 17. Relationship of friction force coefficient and displacement

\subsubsection{Theoretical model}

In order to be applied in practice, it is proposed to take the bilinear elastic-plastic model as the theoretical model of the elastomeric bearing with sliding (as shown in Fig. 18).

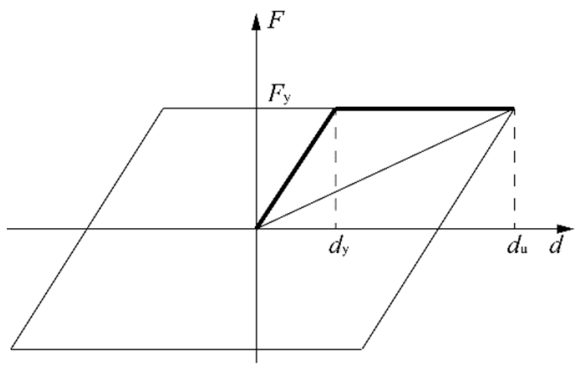

Fig. 18. Theoretical model of the elastomeric bearing with sliding

Before sliding, the displacement of the bearing was mainly the elastomer shear deformation. The slope in the theoretical model is the initial shear stiffness of the bearing $K_{b}$. After the horizontal load larger than the friction force $F_{y}$, the bearings began to slide. Then the slope is close the sliding friction coefficient $\mu_{f}$. At this time, the load-displacement relationship present bilinear shape:

$F_{y}=\mu_{f} R_{d}$ 
$d_{y}=\frac{F_{y}}{K_{b}}=\frac{\left(\mu_{f} R_{d}\right)}{K_{b}}$.

Hear, $F_{y}$ is the friction force between the bearing and the steel pad; $\mu_{f}$ is the friction coefficient; $R_{d}$ is the reaction force; $d_{y}$ is the displacement before sliding; $d_{u}$ is the ultimate displacement; $K_{b}$ is the initial shear stiffness of the bearing.

\section{Conclusions}

Considering the laminated elastomeric bearings of bridges in China, ultimate shear failure and friction sliding tests were conducted. The effect of the energy dissipation was analyzed and compared with lead rubber bearings under cyclic loading. The main conclusions are as follows:

1) Under cyclic horizontal loading, when the shear deformation reached $200 \%$, the outer protective elastomeric layer of the normal laminated elastomeric bearings became separated from the bearing body. When the shear deformation reached $300 \%$ to $400 \%$, the different parts of the bearings failed, causing the shear stiffness and the shear capacity to be completely lost. During the test, the hysteresis curve of the normal laminated elastomeric bearings was narrow zonal, which indicated that the energy dissipation capacity was poor.

2) With the friction sliding, the energy dissipation capacity of the normal laminated elastomeric bearings was close to the lead rubber bearings. The maximum energy dissipation in a single cycle could achieve $126 \%$ of the lead rubber bearing. With an increase in the displacement, the amount of dissipated energy increased, while the shear deformation no longer increased after reaching a maximum. After the test, the bearings remained intact. The hysteresis curves presented a bilinear shape. With an increase in the vertical load, the friction force increased, and the friction coefficient decreased.

3) Under cyclic loading, the energy dissipation capacity of the LRB was stable. At the beginning of the loading, the LRB began dissipating energy. During the test, the appearance of the LRB remained intact. After the test, the LRB essentially returned to its original condition. The hysteresis curve of the LRB was always fuller.

4) The bilinear elastic-plastic model was proposed to take as the theoretical model of the elastomeric bearing with sliding in practice.

5) Although friction sliding causes the laminated elastomeric bearings to dissipate energy, it is difficult to control the displacement. It is necessary to add a retaining system to effectively control the relative displacement between the piers and the girders.

\section{Acknowledgements}

This work is financially supported by the National Natural Science Foundation of China (Grant No. 51408009, 51708516, 51608010), Beijing Natural Science Foundation (Grant No. 8174078) for this study.

\section{References}

[1] Fan L. C., Li J. Z. Analysis of seismic damage and anti-seismic design measures on bridges in Wenchuan. Highway, Vol. 5, 2009, p. 122-128.

[2] Kawashima K. Seismic design and retrofit of bridge. 12th World Conference on Earthquake Engineering, 2000, p. 280-291.

[3] Fäcke A., Baur M., Schlüter F. H. Assessment of bridge performance - seismic isolation versus ductility. 14th World Conference on Earthquake Engineering, 2008, p. 560-579.

[4] Iemura H., Miyamoto A., Akahashi Y. Influence of failure of steel bearings on damage modes of bridges under strong Earthquake motion. Journal of Structural Engineering, Vol. 44, 1998, p. 659-666. 
[5] Kajita Y., Watanabe E., Sugiura K. Seismic response of elevated bridges considering the failure of steel bridges and assessment on effectiveness of fall-off prevention devices. Journal of Structural Engineering, Vol. 23, 1999, p. 903-914.

[6] Okazaii M., Tsuda H., Dogaki M. Seismic response of continuous bridges supported by seismic isolation bearings in consideration of collision between girders. Journal of Structural Engineering., Vol. 48, 2002, p. 899-907.

[7] Kim Sang Hyo, Mha Ho Seong, Lee Sang Woo Effects of bearing damage upon seismic behaviors of a multi-span girder bridge. Engineering Structures, Vol. 28, 2006, p. 1071-1080.

[8] Stanton J. F., Roeder C. W. Elastomeric bearings design, construction, and materials. DC: National Cooperative Highway Research Program 248, Transportation Research Board, National Research Council, Washington, 1982.

[9] Schrage I. Anchoring of Bearing by Friction (Special Publication SP70-12). American Concrete Institute (ACI), Detroit, 1981.

[10] Mori A., Moss P. J., Cooke N. Behavior of bearings used for seismic isolation under shear and axial load. Earthquake Spectra, Vol. 15, Issue 2, 1999, p. 199-224.

[11] Filipov E. T., Hajjar J. F., Steelman J. S. Computational analyses of quasi-isolated bridges with fusing bearing components. Proceedings of the ASCE/SEI Structures Congress, 2011, p. 276-288.

[12] Steelman J. S., Fahnestock L. A., Lafave J. M. Seismic response of bearings for quasi-isolated bridges-testing and components modeling. Proceedings of the ASCE/SEI Structures Congress, 2011, p. 164-178.

[13] Steelman J. S., Fahnestock L. A., Filipov E. T., Lafave J. M., Hajjar J. F., Foutch D. A. Shear and friction response of nonseismic laminated elastomeric bridge bearings subject to seismic demands. Journal of Bridge Engineering, Vol. 8, 2011, p. 612-623.

[14] Buckle I., Nagarajaish S., Ferrell K. Stability of elastomeric isolation bearings: experimental study. Journal of Structural Engineering, Vol. 128, 2002, p. 3-11.

[15] Tang H., Li J. Z. Displacement control method for continuous bridges on laminated rubber bearings under earthquake excitation. China Journal of Highway and Transport, Vol. 26, 2013, p. 110-116.

[16] Fan L. C., Nie L. Y., Li J. Z. Dynamic characteristic analysis of laminated rubber bearing sliding under earthquake. China Journal of Highway and Transport, Vol. 16, 2003, p. 30-35.

[17] Wang D. S., Feng Q. M. Effects of frictional force at movable supports on earthquake response of simply supported reinforced concrete bridges. Earthquake Engineering and Engineering Vibration, Vol. 18, 1998, p. 30-39.

[18] Wang D. S., Guo X., Sun Z. G. Damage to highway bridges during Wenchuan Earthquake. Journal of Earthquake and Engineering Vibration, Vol. 29, 2009, p. 84-94.

[19] Xie X., Wu S. X. Earthquake response of bridge restrainers considering failure of bearings. Journal of Zhejiang University, Vol. 40, 2009, p. 2180-2185.

[20] Huang Y., Wang J. J., Han P. Seismic response analysis of continuous bridges taking account of bearing failure. China Civil Engineering Journal, Vol. 43, 2009, p. 217-223.

[21] Tobias Daniel H., Ralph Anderson E., Hodel Chad E. Overview of earthquake resisting system design and retrofit strategy for bridges in Illinois. Journal of Bridge Engineering, Vol. 9, 2010, p. 147-157.

[22] Ministry of Transport of P. R. China. Series of Elastomeric Pad Bearings for Highway Bridges (JT/T 663-2006). China Communications Press, Beijing, 2007.

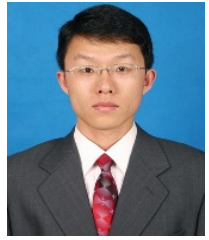

Yue Li received Ph.D. degree in School of Civil and Environmental Engineering, from University of Science and Technology Beijing, China, in 2010. Now he works at North China University of Technology. His current research interests include dynamics, seismic control. 
Qian Li received Master degree in School of Civil Engineering, from Harbin Institute of Technology, China, in 2004. Now she works in bridge engineering center, Research Institute of Highway of Ministry of Communications, China. Her research interests lie in bridge seismic design.

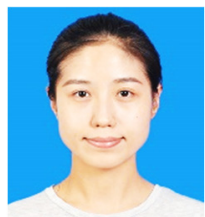

Qiqi Wu is Master student in School of Civil Engineering, North China University of Technology, China. Now she majors in the bridge seismic design. 